\title{
PENGEMBANGAN FUNGSI HUNIAN BERDASARKAN IDENTITAS LOKAL PADA AREA WATERFRONT DI PASAR LAMA TANGERANG
}

\author{
Louis Osvaldo Xavier ${ }^{1}$, Felia Srinaga ${ }^{2}$, Alvar Mensana ${ }^{3}$ \\ 1,2,3. Jurusan Arsitektur, Fakultas Desain, Universitas Pelita Harapan, \\ Jl. M. H. Thamrin Boulevard 1100 Lippo Village, Tangerang \\ Email: louisox04@gmail.com
}

\begin{abstract}
Abstrak
Permasalahan perletakan hunian dan penataan fungsi ruang pada area waterfront di Pasar Lama Tangerang adalah tidak tertatanya hunian dengan baik dan belum dimanfaatkannya tepian sungai Cisadane sebagai salah satu aset lingkungan. Hal tersebut menyebabkan tidak terintegrasi antara area hunian, area berdagang dengan ruang kota sekitarnya (placeness) serta pudarnya identitas Pasar Lama sebagai kawasan Pecinan di tepi Sungai Cisadane. Penelitian ini mengajukan beberapa pertanyaan penelitian, yaitu: apa yang menjadi kriteria hunian pada area waterfront, apa fungsi hunian yang beridentitas dan sesuai pada area waterfront di Pasar Lama, dan bagaimana penerapan konsep fungsi hunian yang beridentitas pada area waterfront di Pasar Lama Tangerang.Penelitian ini mengumpulkan data dari beberapa studi literatur, observasi lapangan dan wawancara. Studi literatur membahas mengenai fungsi hunian, area waterfront dan identitas Pasar Lama.Observasi lapangan dilakukan untuk menguji teori dan menganalisis fungsi hunian, aksesibilitas bangunan, fasilitas penunjang hunian area waterfront dan identitas Pasar Lama. Hasil penelitian ini adalah ditemukannya fungsi-fungsi hunian yang sesuai dengan parameter perancangan hunian pada area waterfront dan identitas Pasar Lama Tangerang. Penelitian ini bertujuan untuk menjadikan kawasan Pasar Lama sebagai area perumahan yang beridentitas, wisata, komersil dengan pengembangan fungsi campuran pada area waterfront di sekitar tepi sungai Cisadane, serta membenahi struktur zonasi dan hubungan area perumahan dengan perdagangan.
\end{abstract}

Kata kunci: fungsi hunian, waterfront, identitas lokal.

\begin{abstract}
Title: The Development of Residential District based on Local Identity on Waterfront Area at Pasar Lama Tangerang
\end{abstract}

The waterfront edges along Cisadane river considered as one of the environmental assets in the area of Pasar Lama (Old Town Market) in the city of Tangerang. However, such valuable asset is neglected due to current urban planning issues specifically on the placement of residential district and land-use planning within Pasar Lama adjacent context. This might caused disintegration between the residential and the commercial areas as the objective of a city to create a sense of place - it's also diminished the identity of Pasar Lama (Old Town Market) as a Chinatown on the banks of the Cisadane River. This research study aim to raise several questions, namely: what are the criteria for a proper residential neighborhood in the context of the waterfront area, what is the function of residential district that has its own particular identity and how does it suitable for the particular context of waterfront area in Pasar Lama (Old Town Market), and how does the concept of identity could be applied on the waterfront area, in the Tangerang's Pasar Lama (Old Town Market). This research study based on data collected from literature studies, field observations and on-site interview. The literature study discuss the functions of identity for a residential district, waterfront area and Pasar Lama (Old Town Market). Field observation studies were carried out to examine the theory and analyze the function of residential neighborhood, building accessibility, supporting facilities for residential areas, and Pasar Lama (Old Town Market) identity. The results of this study are finding the residential functions in which 
aligned with the parameters on residential design in the waterfront area and the local identity of the Tangerang Pasar Lama (Old Town Market). It aims to make the Pasar Lama (Old Town Market) areas to create and establish the local identity reflecting tourism, commercial and residential neighborhood, in addition to the mixed-use development on the waterfront area around the banks of the Cisadane river. Lastly, this research study also attempt to re-configure the landuse planning as well as strategize on how to locate the residential district that supports the relationship to its adjacent commercial areas.

Keywords: dwelling functions, waterfront, local identity.

\section{Pendahuluan}

Perancangan hunian dan perletakan fungsi ruang yang tidak tertata dengan baik terutama pada area waterfront menyebabkan hubungan dan zonasi area suatu kawasan menjadi tidak terstruktur dengan baik. Perkembangan suatu kawasan yang kurang memperhatikan karaktersitik kawasan menyebabkan pudarnya identitas lokal kawasan tersebut. Permasalahan ini tidak lepas dari perancangan beberapa bagian kota di Indonesia terutama adanya fenomena pertumbuhan pemukiman atau hunian yang tidak teratur, termasuk pada area tepian sungai Pasar Lama Tangerang. Pertumbuhan pemukiman warga yang berkembang dan menghuni di tepi sungai secara organik dan hunian yang tidak lagi berfungsi secara tunggal sebagai tempat tinggal namun bisa berfungsi dalam berbagai hal menyebabkan sulitnya pelaksanaan perancangan kota yang baik dan tepat. Dalam penelitian ini akan dilakukan riset yang menghasilkan rancangan fungsi hunian yang sesuai dengan pengembangan hunian pada area waterfront dengan memperhatikan identitas kawasannya. Diharapkan penelitian ini menjadi solusi dalam membenahi struktur hubungan dan zonasi pada area waterfront dan meningkatkan citra kawasan yang memperhatikan identitasnya.
Pada penelitian ini kawasan area waterfront Pasar Lama Tangerang menjadi lokasi obyek penelitian yakni perumahan yang berada di tepian Sungai Cisadane. Keberadaan Sungai Cisadane sudah melekat dalam perkembangan kawasan Pasar Lama Tangerang seperti kegiatan budaya, perdagangan, dan keagamaan masyarakat Tionghoa yang sudah ada sejak 600 tahun yang lalu. Walapun Sungai Cisadane dengan kegiatan, keadaan fisik dan maknanya merupakan salah satu identitas dari Pasar Lama Tangerang, namun dalam perkembangan perancangan kota terutama hunian dan perletakan fungsi ruang belum ada tindakan konkrit pemerintah dalam mengolah potensi Sungai Cisadane sebagai daya tarik kawasan. Permasalahan Pasar Lama Tangerang akan pengembangan fungsi hunian yang beridentitas pada area waterfront menjadi dasar untuk obyek penelitian ini. Fokus penelitian ini adalah pada fungsi berhuni berdasarkan identitas pada waterfront area di Pasar Lama Tangerang.

Hasil yang diharapkan dari penelitian ini adalah ditemukannya fungsi hunian yang ber-identitas dan sesuai kriteria penataan hunian pada area waterfront. Penelitian ini bertujuan untuk menjadikan kawasan Pasar Lama sebagai area hunian, komersil, dan wisata dengan pengembangan fungsifungsi hunian yang beridentitas pada 
area waterfront sekitar tepi Sungai Cisadane dengan membenahi struktur zonasi dan hubungan area perumahan dan perdagangan di Pasar Lama Tangerang.

\section{Kajian Teori}

Pada kajian teori akan dibahas mengenai teori yang mendukung pengembangan fungsi hunian berdasarkan identitas lokal pada area waterfront di Pasar Lama Tangerang. Pembahasan kriteria fungsi hunian yang beridentitas pada area waterfront adalah berdasarkan kajian fungsifungsi hunian yang sesuai pada area waterfront dan kajian tentang identitas kawasan pada area waterfront.

Berdasarkan hasil kajian teori (Carmona, Matthew, Tim Heath, Taner Oc, and Steve Tiesdell (2003); Dwitama, Daryl (2017); Khaliesh, Hamdil (2014); Ligo, Larry L. (1984); Lynch, Kevin (1960)), disimpulkan kriteria fungsi hunian berdasarkan identitas lokal pada area waterfront adalah citra dan makna (pengalaman ruang), bangunan (kepadatan bangunan, penataan bangunan, orientasi bangunan, fasad bangunan, kenyamanan, penataan dan organisasi ruang dan abstraksi bentuk berdasarkan konteks), uses and activity (jenis fungsi, keberagaman aktivitas, aktivitas hidup dan dinamis, dan zonasi dan hubungan antar ruang), aksesibilitas dan lingkage (pengembangan akses, pola jalan dan pembagian akses), sosial budaya (fasilitas penunjang) dan letak geografis dan lanskap (kualitas lanskap, sempadan bangunan, kenyamanan dan kondisi tapak).
Tabel 1. Kesimpulan kriteria penelitian berdasarkan kajian teori

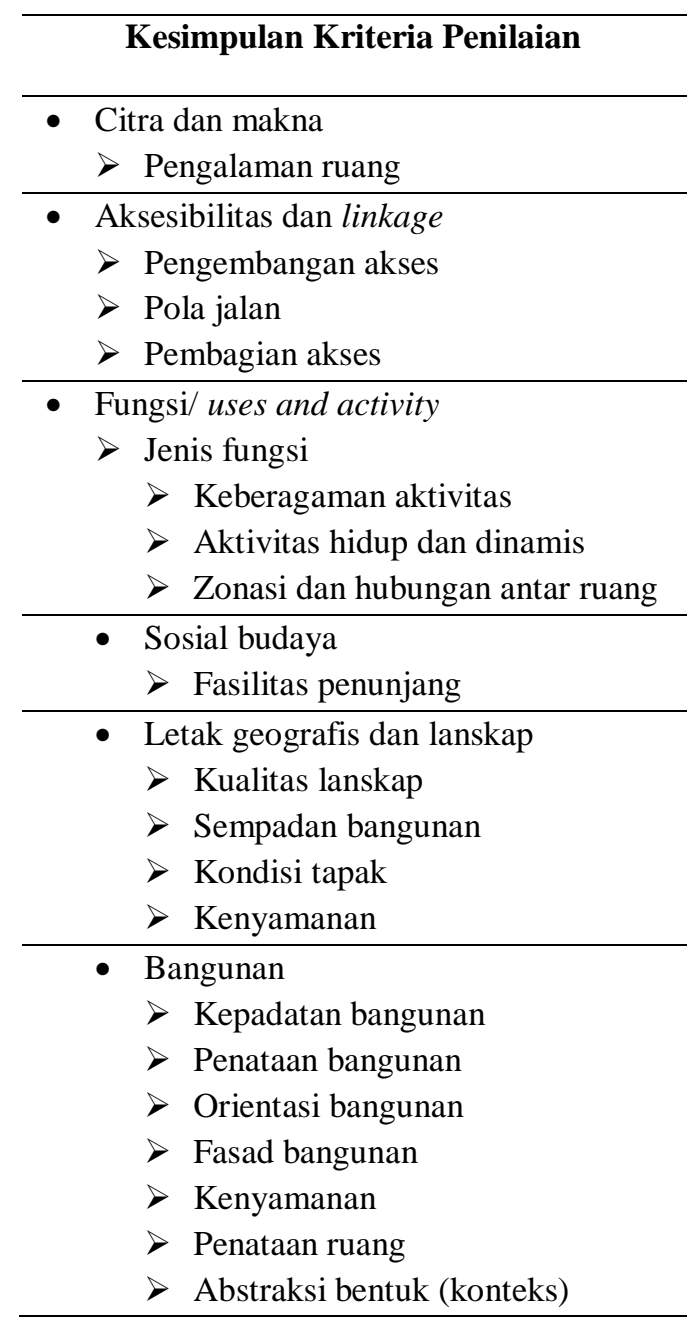

Sumber: Hasil analisis, 2019

\section{Metode dan konteks kawasan studi}

Metode penelitian dalam analisis site berupa observasi site, wawancara dan penyebaran angket. Analisis site merupakan pembahasan masalah yang ada pada site berdasarkan kesimpulan kriteria penelitian dalam kajian teori. Observasi site, wawancara dan penyebaran angket bertujuan untuk mendapatkan data yang valid mengenai permasalahan secara fisik maupun persepsi penghuni yang tinggal pada site. Hasil dari metode penelitian akan menghasilkan 
kesimpulan dan solusi desain yang ditawarkan untuk merealisasikan penelitian dalam perancangan arsitektur.

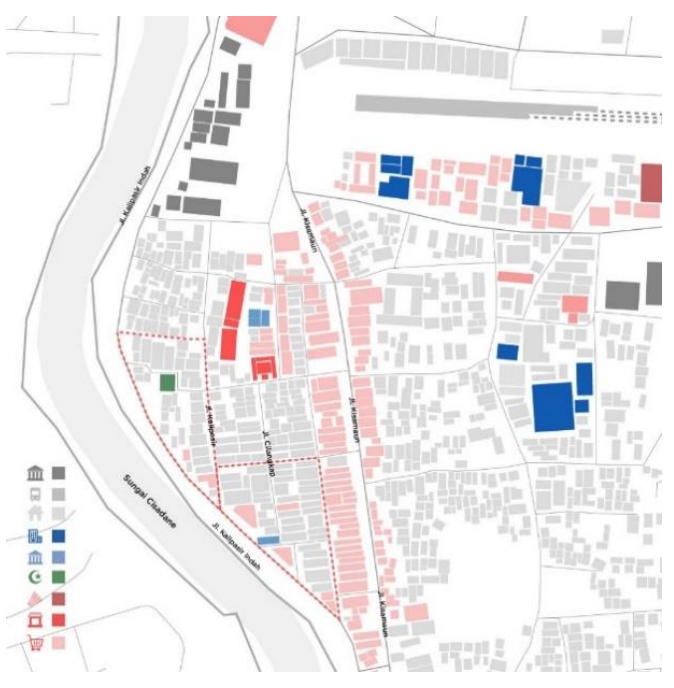

Gambar 1. Noly map Pasar Lama Tangerang

Sumber: Hasil analisis, 2019

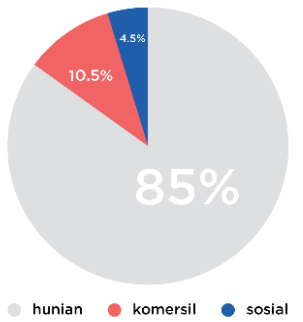

Gambar 2. Diagram zoning kawasan Pasar Lama

Sumber: Hasil analisis, 2019

Berdasarkan hasil analisis site yang didasarkan pada observasi site, wawancara dan penyebaran kuisioner, kriteria fungsi hunian yang beridentitas pada area waterfront antra lain: citra dan makna, uses and activity, aksesibilitas dan lingkage, sosial budaya, dan letak geografis dan lanskap, dan bangunan. Berikut pemaparan solusi desain dalam tabel 2 yang akan diterapkan dalam perancangan penelitian.

Tabel 2. Solusi desain berdasarkan analisis site

\begin{tabular}{|c|c|c|}
\hline $\begin{array}{l}\text { Kesi } \\
\text { Pene } \\
\text { Hun } \\
\text { Iden } \\
\text { Area }\end{array}$ & $\begin{array}{l}\text { impulan Kriteria } \\
\text { elitian: Fungsi } \\
\text { iian berdasarkan } \\
\text { titas Lokal pada } \\
\text { Waterfront }\end{array}$ & Solusi Desain \\
\hline 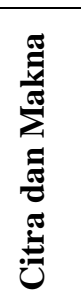 & $\begin{array}{l}>\text { Pengalaman } \\
\text { Ruang }\end{array}$ & $\begin{array}{l}\text { Menjadikan kawasan dalam site sebagai suntikan akupuntur } \\
\text { kota berupa pengembangan fungsi hunian yang juga } \\
\text { memperhatikan bangunan tepi air dan kawasan pecinan. }\end{array}$ \\
\hline 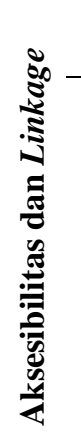 & $\begin{aligned}> & \begin{array}{l}\text { Pengembangan } \\
\text { Akses }\end{array} \\
> & \text { Pembagian } \\
& \text { Akses }\end{aligned}$ & $\begin{array}{l}\text { Akses mobil hanya ada dari Jl. Kalipasir Indah menuju lahan } \\
\text { parkir yang ada di bagian selatan site. Sehingga area dalam site } \\
\text { diperuntukan hanya untuk pedestrian dan jalur pedestrian } \\
\text { minimal memiliki tiga akses. } \\
\text { Jalur pedestrian pada Jl. Cilangkap di dalam site diperbesar } \\
\text { menjadi } 6 \text { meter untuk menyesuaikan zonasi fungsi untuk } \\
\text { komersil. } \\
>\text { Penambahan akses privat bagi penghuni untuk masuk ke } \\
\text { kawasan perumahan. } \\
>\begin{array}{l}\text { Penambahan akses menuju badan air berupa jalur pedestrian/ } \\
\text { tangga/ ramp maupun jembatan. }\end{array}\end{array}$ \\
\hline
\end{tabular}




\begin{tabular}{lll}
\hline$>$ Pola Jalan & $>$ & Menetapkan pola jalan semi latice baik pada zona publik pada \\
& Jl. Cilangkap (fungsi komersil dan sosial) maupun zona privat \\
& di dalam kawasan hunian (fungsi berhuni). \\
\hline$>$ Jenis Fungsi & $>$ & Mempertahankan dan mengembangkan jenis fungsi di dalam \\
& site yaitu berhuni, komersil dan sosial sesuai dengan jumlah \\
& penduduk dan persentase jenis fungsi pada site.
\end{tabular}

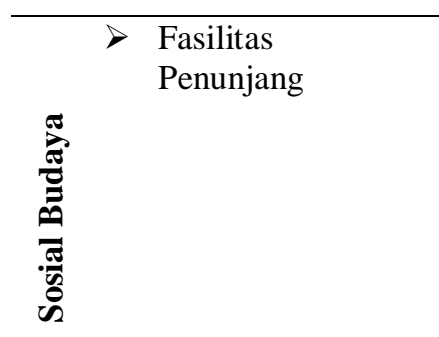

Fasilitas transportasi berupa halte angkutan umum diletakan dekat dengan perimeter Jl. Kalipasir Indah dekat dengan entrance jalur pedestrian agar lebih mudah dicapai dengan berjalan kaki.

$>$ Fasilitas penunjang yang akan ditambah didalam site berupa wc umum ditempatkan dengan area komersil dan sosial dalam site. Terdapat taman pada kawasan tepian air sebagai area publik untuk pengunjung. Tempat-tempat duduk akan ditempatkan di area komersil dan sosial.

\begin{tabular}{lll}
\hline $\begin{array}{l}\text { Kenyaman } \\
\text { an }\end{array}$ & $>\begin{array}{l}\text { Menempatkan area peneduh (bangunan 2-3 lantai dengan } \\
\text { koridor peneduh dan pohon besar) disepanjang jalur pedestrian } \\
\text { luar bangunan. }\end{array}$ \\
\hline$>$ Kualitas & $>\begin{array}{l}\text { Menempatkan courtyard pada area kawasan bangunan } \\
\text { terutama pada bagian dalam bangunan dan area transisi antar } \\
\text { bangunan/ tempat. }\end{array}$ \\
\hline$>$ Sempadan & $>$ Membatasi area dibangun dalam site maksimal 20 meter dari \\
& jarak antara bangunan tepi air sampai titik tertinggi pasang air. \\
\hline$>$ Kondisi Tapak & $>$ Perletakan antar pohon dibuat renggang sebesar 10 meter. \\
& $>\begin{array}{l}\text { Perletakan vegetasi/ pohon didalam site lebih merata terutama } \\
\text { pada area komersil dan sosial di Jl. Cilangkap dan di dalam } \\
\text { halaman dan RTH pada area hunian. }\end{array}$ \\
& $>\begin{array}{l}\text { Penambahan lanskap dan area pengerasaan pada area dekat } \\
\text { badan air sepanjang } 5 \text { meter. }\end{array}$ \\
& $>\begin{array}{l}\text { Penyesuaian bentuk atap yang lebih lebar antara } 20 \text { cm-100 cm } \\
\text { (tritisan) untuk mengatasi panas dan tampias air hujan. }\end{array}$
\end{tabular}

\footnotetext{
$>$ Kepadatan $>$ Mengatur kepadatan bangunan maksimal 25\% pada tepian air. Bangunan
} 


\begin{tabular}{|c|c|c|}
\hline & $\begin{array}{l}\text { Penataan } \\
\text { Bangunan }\end{array}$ & $\begin{array}{l}>\text { Tinggi bangunan antara 6-10 meter (dua sampai tiga lantai). } \\
>\text { Atap bangunan menggunakan renzi roof. } \\
>\text { Bentuk bangunan bersifat single (alternatif bentuk L, linear dan } \\
\text { memusat). } \\
>\text { Struktur bangunan terlihat dari eksterior bangunan. }\end{array}$ \\
\hline$>$ & $\begin{array}{l}\text { Orientasi } \\
\text { Bangunan }\end{array}$ & $\begin{array}{l}\text { Bangunan yang berada di kawasan tepian air harus menghadap } \\
\text { Sungai Cisadane. }\end{array}$ \\
\hline$>$ & $\begin{array}{l}\text { Fasad } \\
\text { Bangunan }\end{array}$ & $\begin{array}{l}\text { Menggunakan warna alami dan material alami pada bangunan } \\
\text { seperti cat warna putih (netral), material alami seperti batu } \\
\text { alam dan kayu. } \\
\text { Memperbanyak bukaan pada fasad bangunan. }\end{array}$ \\
\hline$>$ & Kenyamanan & $\begin{array}{l}\text { Strategi penghawaan ruang dalam bangunan menggunakan } \\
\text { void dan penghawaan vertikal untuk mengeluarkan udara } \\
\text { panas. } \\
\text { Memperbanyak bukaan pada eksterior bangunan untuk } \\
\text { memperbanyak intensitas cahaya matahari masuk ke dalam } \\
\text { ruang dalam bangunan (minimal: atap dan fasad). }\end{array}$ \\
\hline$>$ & $\begin{array}{l}\text { Penataan dan } \\
\text { Organiasi } \\
\text { Ruang }\end{array}$ & $\begin{array}{l}\text { Menempatkan ruang berdasarkan aksis bangunan. Fungsi ruang } \\
\text { dalam dikelompokan berdasarkan modul-modul ruang dan } \\
\text { perletakan modul-modul ruang berdasarkan hirarki ruang yaitu } \\
\text { public-private. } \\
\text { Ruangan yang dekat pintu masuk adalah ruang yang lebih } \\
\text { publik dan semakin dalam ruangannya maka semakin privat. }\end{array}$ \\
\hline$>$ & $\begin{array}{l}\text { Abstrasi Bentuk } \\
\text { (Konteks) }\end{array}$ & $\begin{array}{l}\text { Menjadikan Sungai Cisadane sebagai konteks dalam abstraksi } \\
\text { bentuk. } \\
>\text { Abstrak bentuk dari Sungai Cisadane adalah lengkung dan arc. } \\
>\text { Penggunaan lengkung dan arc akan diterapkan pada elemen } \\
\text { bangunan seperti atap dan badan bangunan. }\end{array}$ \\
\hline
\end{tabular}

Sumber: Hasil analisis, 2019

\section{Pembahasan}

Pembahasan mengenai konsep desain yang didasari dari hasil analisis site akan dibagi menjadi dua bagian, yaitu konsep desain makro dan konsep desain mikro. Konsep desain makro membahas mengenai konsep hubungan dan dampak yang diharapkan dalam perancangan site dengan konteks/ kawasan di sekitarnya. Pembahasan konsep makro meliputi: citra dan makna kawasan, zonasi dan hubungan antar ruang. Sementara konsep desain mikro akan membahas mengenai konsep-konsep desain yang mendukung keterbangunan dan perencanaan dalam perancangan, meliputi: aksesibilitas, fungsi/ uses and activity, lanskap dan fasilitas penunjang, dan bangunan. Konsepkonsep desain makro dan mikro yang ada akan dievaluasi secara menyeluruh dan hasil dari evaluasi tersebut akan menjadi dasar dalam perancangan.

\section{Konsep Desain Makro: Citra dan Makna}

Dalam kesimpulan solusi desain mengenai citra dan makna, meningkatkan citra kawasan yaitu mempertahankan dan mengembangkan citra site yang merupakan kawasan tepi air (Sungai Cisadane) dan kawasan 
Pecinan dengan menjadikan kawasan dalam site sebagai suntikan akupuntur kota berupa pengembangan fungsi hunian yang juga memperhatikan bangunan tepi air dan kawasan pecinan.

Selain citra, kawasan juga harus meningkatkan makna bagi penghuni dalam site dan sekitarnya. Makna yang perlu dipertahankan adalah pengalaman dan aktivitas keseharian penghuni. Pengalaman tersebut berupa bentuk ruang dan bangunan yang ada, terutama bangunan bertemakan Arsitektur Cina yang dikembangkan, aktivitas dan kegiatan yang ada serta keadaan fisik site (seperti akses, fasilitas, dan pembangunan yang memperhatikan kondisi tapak yaitu lanskap, vegetasi dan area hijau, pembangunan kawasan tepi air dan iklim pada tapak). Dari pembahasan ini, konsep desain didasarkan pada rancangan yang mengembangkan site berdasarkan pengembangan fungsi hunian yang memperhatikan pengembangan bangunan tepi air dan pengembangan kawasan Pecinan sebagai identitas lokal kawasan.

\section{Konsep Desain Makro: Zonasi dan Hubungan antar Ruang}

Solusi desain zonasi dan hubungan antar ruang adalah membagi letak kawasan berdasarkan jenis fungsi (berhuni, komersil dan sosial) dan public-private bangunan. Berdasarkan solusi desain di atas, terdapat konsep desain zonasi dan hubungan antar ruang, yaitu:

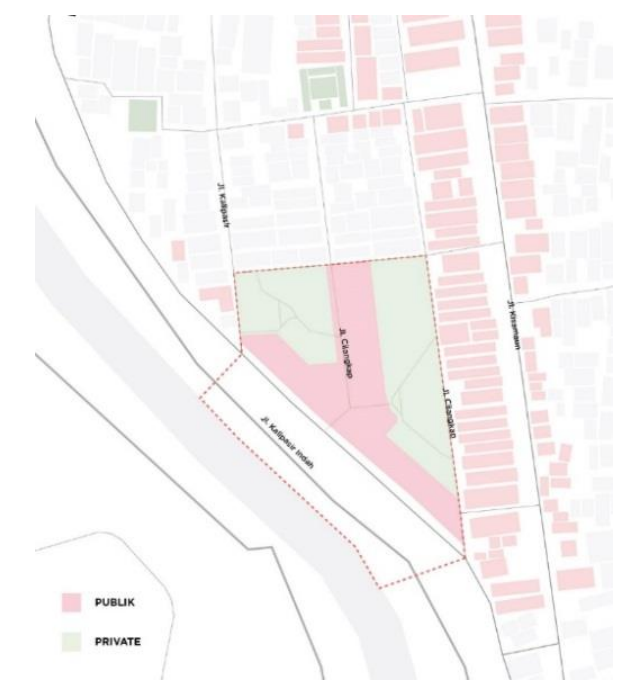

Gambar 3. Noly map alternatif konsep desain zonasi dan hubungan antar ruang Sumber: Hasil analisis, 2019

Perletakan zonasi fungsi yang bersifat publik berada di muka site hingga bagian dalam site dan zonasi fungsi yang bersifat privat berada di bagian dalam site. Konsep desain di atas adalah ingin menghidupkan aktivitas di bagian luar hingga dalam site sehingga lebih mengundang pengunjung/ orang untuk singgah. Pada bagian muka site diletakan aktivitas publik yang bersifat komersil untuk menarik pengunjung masuk hingga pada site yang terdalam.

Jika dilihat berdasarkan zonasi fungsi kawasan di sekitar site, kawasan site dari arah timur merupakan bagian belakang bangunan dari area komersil yaitu ruko-ruko komersil yang menghadap J1. Kisamaun. Maka, pada bagian belakang adalah area hunian dan area yang lebih privat bagi pemilik rumah. Dari arah utara hingga barat, zonasi fungsi kawasan sekitar site merupakan hunian/ rumah tinggal bersifat privat. Perletakan zonasi fungsi privat yang tepat pada site adalah pada bagian timur, utara dan barat site sementara zonasi fungsi publik seperti komersil/ sosial berada dibagian selatan. 
Konsep Desain Mikro: Aksesibilitas

Pada konsep desain mikro, perletakan akses mobil hanya pada bagian selatan site yang berada pada Jl. Kalipasir Indah. Mobil tidak bisa memasuki area di dalam site. Kedua alternatif samasama memperbesar perletakan parkir kendaraan bermotor di bagian selatan site dan jalan pedestrian sebesar 6 meter pada Jl. Cilangkap. Pada konsep desain perletakan akses juga memiliki akses privat pada area hunian, akses menuju badan air dan bersifat semilattice dalam mengkoneksi antar bangunan.

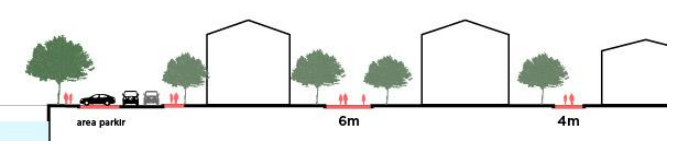

Gambar 4. Diagam potongan site Sumber: Hasil analisis, 2019

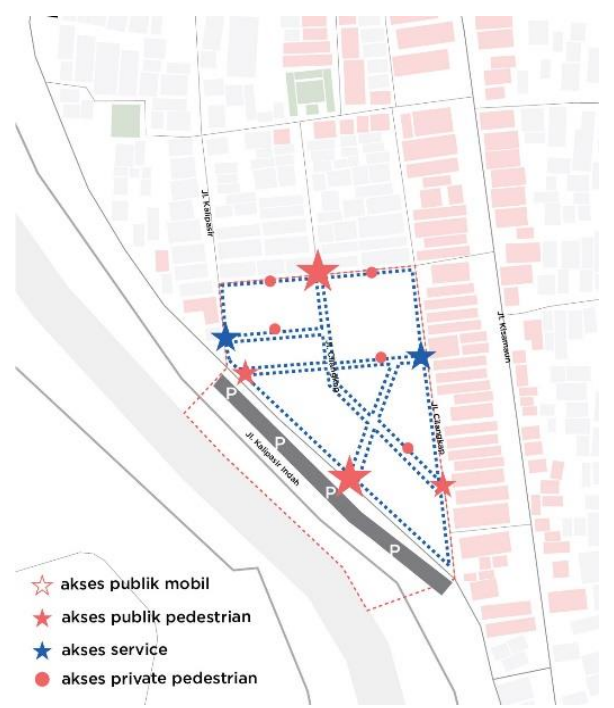

Gambar 5. Noly map konsep desain aksesibilitas

Sumber: Hasil analisis, 2019

Pada konsep desain ini, terdapat 2 akses masuk utama, 2 akses masuk sekunder dan 2 akses service bagi area komersil. Banyaknya akses masuk kedalam site akan meningkatkan kemudahan pencapaian ke dalam site oleh pejalan kaki dan akses service yang diperlukan untuk bangunan komersil yang bersifat publik.

\section{Konsep Desain Mikro: Fungsi/ uses and Activity}

Konsep desain mikro mengenai fungsi/ uses and activity didasari oleh solusi desain berupa penetapan dan pengembangan jenis fungsi bangunan/ programming yang ada pada site dan peningkatan intesitas aktivitas site terutama kegiatan komersil agar aktivitas dalam site menjadi hidup dan beragam.

Berdasarkan solusi desain ini, jenis fungsi pada site didominasi dengan fungsi hunian yang menampung sekitar 132 jiwa, dengan 44 bangunan yang berpadu antara fungsi hunian dan hunian-komersil (ruko toko dan restoran), fungsi sosial berupa Museum Roemboer yang dipertahankan dan dikembangan serta pengembangan fungsi hunian pada site berupa fungsi berhuni yaitu hostel. Persentase fungsi hunian harus lebih besar dibandingkan dengan fungsi bangunan yang lain sehingga dalam perancangan mengenai fungsi/ uses and activity, penyebaran fungsi hunian pada bangunan menjadi lebih merata dalam site. Berikut merupakan programming dalam site, yaitu:

1. Fungsi hunian berupa rumah tinggal (22 unit) yang memiliki fungsi tunggal yaitu berhuni. Dalam rumah terdiri dari 3 penghuni dengan luas lahan 110 $\mathrm{m}^{2}$ dan luas bangunan $120 \mathrm{~m}^{2}$ setinggi 2 lantai.

2. Fungsi komersil berupa rumah toko (restoran) (9 unit) yang memiliki fungsi berhuni dan komersil. Dalam rumah terdiri dari 3 penghuni dengan luas lahan 100 $\mathrm{m}^{2}$ dan luas bangunan $200 \mathrm{~m}^{2}$ setinggi 2 lantai. 
3. Fungsi komersil berupa rumah toko (toko) (6 unit) yang memiliki fungsi berhuni dan komersil. Dalam rumah terdiri dari 3 penghuni dengan luas lahan 120 $\mathrm{m}^{2}$ dan luas bangunan $200 \mathrm{~m}^{2}$ setinggi 2 lantai.

4. Fungsi komersil berupa hostel merupakan salah satu pengembangan fungsi berhuni dan komersil pada site. Hostel (1 unit) dengan luas lahan $600 \mathrm{~m}^{2}$ dan luas bangunan $900 \mathrm{~m}^{2}$ setinggi 3 lantai.

5. Fungsi sosial berupa Museum Roemboer (1 unit) dengan luas lahan $200 \mathrm{~m}^{2}$ dan luas bangunan $360 \mathrm{~m}^{2}$ setinggi 3 lantai.

Berdasarkan solusi desain mengenai aktivitas yang hidup, jenis fungsi yang bersifat publik seperti hostel, ruko dan museum memiliki jam buka dari pagi hingga malam. Diharapkan aktivitas di dalam site menjadi lebih intens pada area publik dibanding dengan keadaan site saat ini yang kurang intensitas aktivitasnya. Berikut konsep desain perletakan program dalam site bedasarkan konsep desain mengenai program pada site, yaitu:

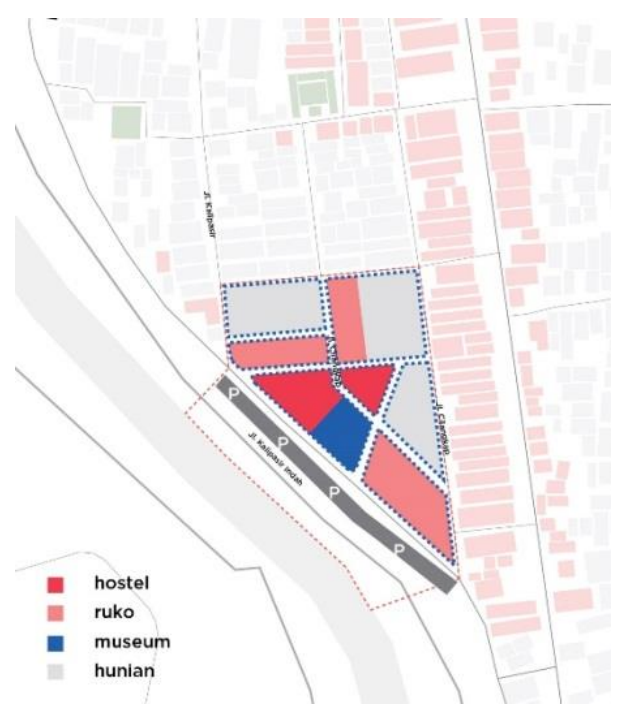

Gambar 6. Noly map konsep desain program pada site

Sumber: Hasil analisis, 2019
Pada konsep desain program pada site, perletakan fungsi komersil berupa ruko dan Museum Roemboer dan hostel berada di bagian selatan site menghadap Sungai Cisadane. Sementara ruko komersil berada dibagian tengah site pada Jl. Cilangkap. Pada bagian timur, utara dan barat site dipenuhi oleh rumah sebagai fungsi hunian. Konsep desain juga memperhatikan kemerataan orientasi bangunan yang merata pada setiap fungsi. Seperti pada fungsi komersil berupa ruko, Museum Roemboer dan hostel berada di bagian selatan site menghadap Sungai Cisadane lebih memungkinkan memiliki orientasi menghadap tepi air.

\section{Konsep Desain Mikro: Fasilitas Penunjang}

Konsep desain mikro mengenai fasilitas penunjang yang didasari oleh beberapa solusi desain, yaitu: pengadaan fasilitas transportasi berupa halte angkutan umum diletakan dekat dengan perimeter Jl. Kalipasir Indah dekat dengan entrance jalur pedestrian agar lebih mudah dicapai dengan berjalan kaki dan penambahan fasilitas penunjang di dalam site berupa wc umum yang ditempatkan pada area komersil dan sosial dalam site.

Terdapat taman pada kawasan tepian air sebagai area publik untuk pengunjung. Pembahasan taman akan lebih detail dibahas pada pembahasan lanskap. Tempat-tempat duduk akan ditempatkan di area komersil dan sosial. Berdasarkan pemaparan solusi desain di atas, berikut adalah konsep desain mengenai fasilitas penunjang dan fasilitas transportasi, yaitu: pada alternatif ini, penyebaran perletakan tempat duduk lebih merata baik pada area-area komersil dan area taman pada tepi sungai dan taman dalam site. Konsep desain pada setiap 
bangunan komersil di dalam site memiliki wc yang dapat digunakan secara umum. Taman pada kawasan merupakan fasilitas rekreasi bagi pengunjung termasuk pada tepian air.

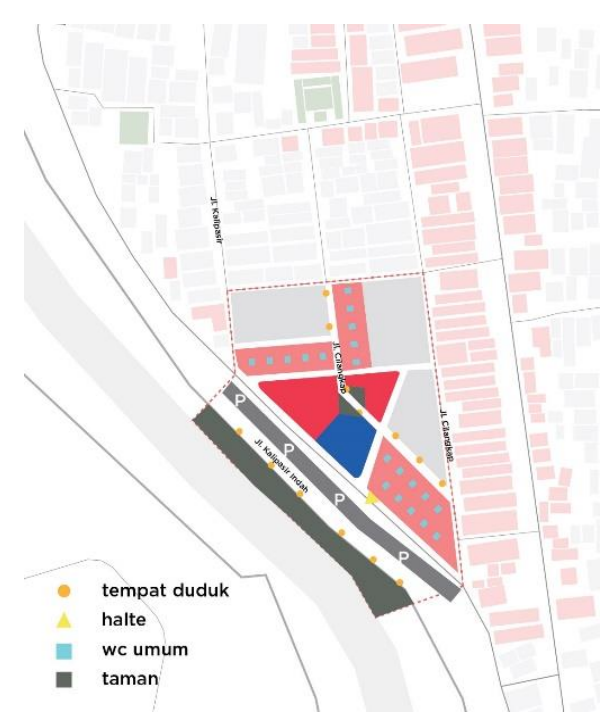

Gambar 7. Noly map konsep desain fasilitas penunjang pada site Sumber: Hasil analisis, 2019

\section{Konsep Desain Mikro: Lanskap}

Konsep desian lanksap mengenai penempatan courtyard dalam bangunan akan dibahas lebih dalam pada pembahasan konsep bangunan. Setiap bangunan yang ada di dalam site harus memiliki courtyard sebagai salah satu kriteria dalam bangunan Arsitektur Cina. Sehingga, hanya ukuran courtyard saja yang disesuaikan pada perletakan dalam bangunan terutama disesuaikan dengan $\mathrm{KDH}$ pada jenis fungsi bangunan tersebut. Sementara courtyard pada bagian luar bangunan yang berupa area RTH/ bukan area pengerasan ditempatkan sebagai ruang transisi antar bangunan/ tempat. Berikut konsep desain mengenai courtyard bagian luar bangunan dan lanksap tepi air, yaitu:

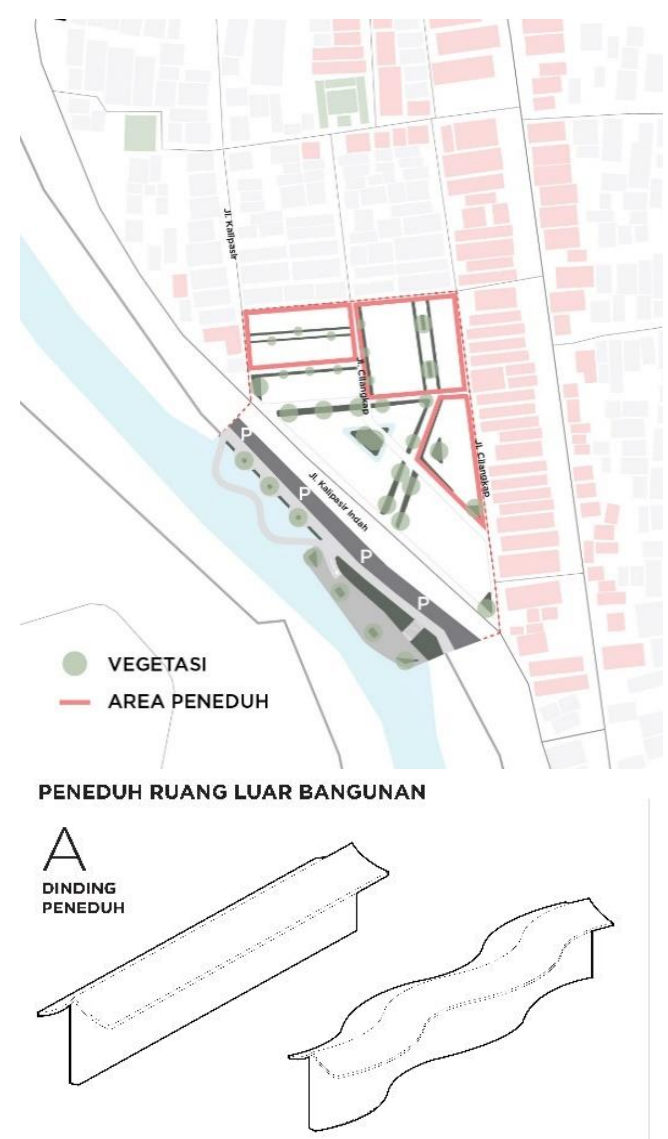

Gambar 8. Noly map konsep desain lanskap Sumber: Hasil analisis, 2019

Konsep desain lanskap, courtyard dan RTH yang ada pada sisi bangunan digunakan untuk memberi penguat orientasi dari jalur pedestrian, ruang transisi menuju suatu tempat dan menjadi batas antara bangunan dengan jalan. Pada bagian taman terdapat penggunaan elemen air sebagai penyatu softscape dengan bangunan sekitarnya. Selain itu, terdapat beberapa titik area hijau yang berupa taman untuk dijadikan ruang duduk. Dalam pengembangan lanksap tepi air terdapat area perkerasan sejauh 5 meter yang memiliki beberapa ruang duduk dan vegetasi. Selain itu, akses menuju tempat tersebut dapat menggunakan ramp, jembatan maupun tangga. Area courtyard dan RTH merupakan ruang transisi antar bangunan/ tempat dan 
terdapat area perkerasan di sepanjang tepi air pada site yang dapat dicapai hanya menggunakan tangga.

Konsep desain mengenai area peneduh pada bagian luar bangunan bertujuan untuk menjaga kenyamanan suhu thermal dengan cara mendapatkan shading maupun terhindar dari air hujan. Bentuk dari konsep desain di atas dapat dibagi menjadi area peneduh alami berupa pohon dan man-made, yaitu koridor peneduh dan atap bangunan. Pada konsep desain di atas, vegetasi diletakkan secara konsisten pada courtyard tiap bangunan dan pada area RTH, serta tidak membangun bangunan pada sempadan bangunan dalam jarak 20 meter dari badan air. Vegetasi diletakkan berjarak kurang lebih 10 meter agar tidak menghalangi view. Selain itu, pada site digunakan dinding pada perimeter batas kavling pada tepi bangunan dengan jalan yang berfungsi sebagai pembatas antar zona hunian dan zona komersil. Dinding tersebut diberi atap dengan lebar sekitar $100 \mathrm{~cm}$. Bentuk dinding dan atap dinding tersebut memiliki alternatif yang disesuaikan dengan abstraksi dalam perancangan.

\section{Konsep Desain Mikro: Bangunan}

Konsep desain mikro mengenai bangunan didasari oleh solusi desain yang dibahas pada analisis site.Tinggi dan bentuk bangunan pada site setinggi 2-3 lantai (antara 6 -10 meter) dan bentuk bangunan pada site berupa linear, L ataupun persegi/ memusat yang merupakan single building. Penetapan tinggi dan bentuk bangunan disesuaikan dengan fungsi bangunan pada keadaan bangunan eksisting (ruko, museum dan rumah) maupun perancangan bangunan baru seperti hostel.
Berdasarkan analisis site dan solusi desain yang sebelumnya telah dibahas pada bagian analisis site, konsep desain pada bangunan akan kepadatan bangunan pada kawasan tepi air maksimal $25 \%$, tujuannya adalah agar kawasan tepi air tetap memberikan ruang untuk melihat view badan air. Hal ini sebelumnya, pada bagian konsep desain mengenai bentuk bangunan, telah ditetapkan berdasarkan fungsi bangunan. Maka, pembangunan pada area tepian air pada site harus memperhatikan kepadatan bangunan dan bentuk bangunan. Terdapat dua alternatif mengenai konsep desain mengenai perletakan bangunan, yaitu:

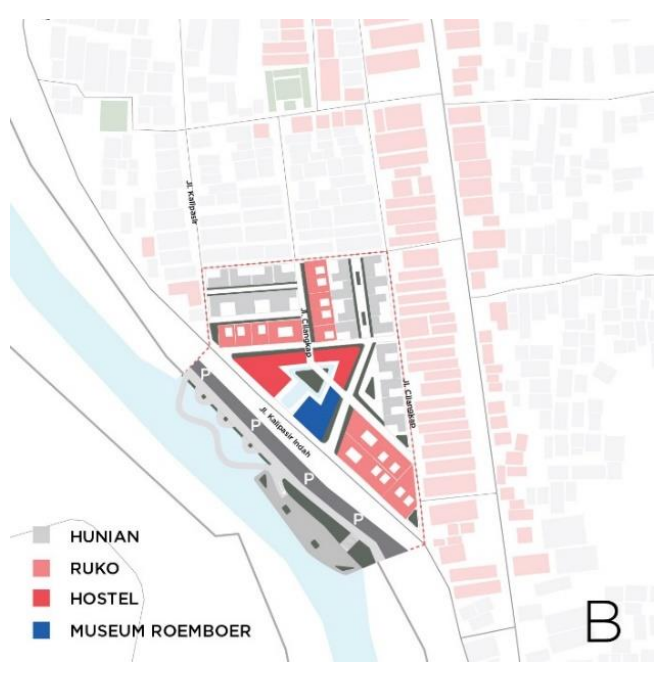

\section{Gambar 9. Noly map konsep desain bangunan: perletakan bangunan Sumber: Hasil analisis, 2019}

Dari perletakan bangunan pada konsep desain diatas terlihat penempatan bangunan sesuai dengan area/zonasi fungsinya masing masing. Area privat yang berupa hunian dilingkupi oleh dinding yang berfungsi sebagai pembatas antara area publik dan privat sehingga zonasi antar ruang publik dan privat lebih jelas. Kepadatan bangunan pada tepian air pada kedua alternatif sudah dibawah $25 \%$ karena pada bangunan tepi air, beberapa bangunan 
memberikan jarak antar bangunan sebelahnya sehingga masih dapat melihat view kepada badan air dari dalam site. Kedua alternatif memberikan setback sebesar 3 meter dari tepi Jl. Kalipasir Indah sehingga dapat digunakan untuk memudahkan ketercapaian pejalan kaki menuju site. Massa bangunan hostel dan museum dipisahkan oleh lanksap sehingga selain tidak massive juga dapat memberikan view untuk bangian hostel di bagaian tengah site dan memberikan jalur akses khusus untuk pengunjung yang ingin ke hostel/museum.

Solusi desain dalam keterbukaan struktur pada eksterior bangunan dan warna, juga material alami pada fasad dibuat berdasarkan karakteristik bangunan Arsitektur Cina, yaitu memperlihatkan struktur utama bangunan yang dibahas di atas.
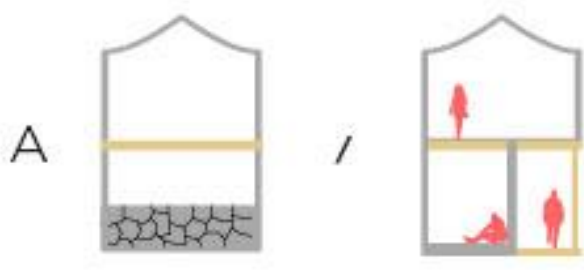

Gambar 10. Konsep desain fasad bangunan Sumber: Hasil analisis, 2019

Pada konsep desain fasad ini, fasad pada bangunan mengekspos pembalokan dari kayu dan mengunakan cat warna putih sebagai warna natural/alami dan material batu alam sebagai fasad dinding. Kemudian di bagian dalam, kolom kayu digunakan pada koridor dalam bangunan dan mengekspos pembalokan kayu dalam bangunan. Pada struktur bangunan, kolom dalam bangunan digantikan dengan bearing wall dengan material precast concrete dan material dindingnya berupa batu bata.

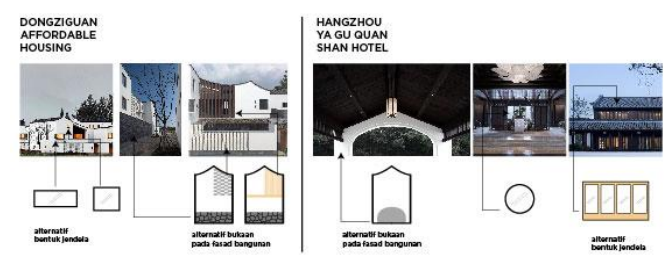

Gambar 11. Konsep desain bukaan eksterior bangunan

Sumber: Hasil analisis, 2019

Solusi desain mengenai kenyamanan ruang dalam bangunan, yaitu strategi penghawaan ruang dalam bangunan menggunakan void dan penghawaan vertikal untuk mengeluarkan udara panas, memperbanyak bukaan pada eksterior bangunan untuk memperbanyak intensitas cahaya matahari masuk ke dalam ruang dalam bangunan (minmal: atap dan fasad).

Berdasarkan pembahasan mengenai void dan penghawaan vertical, maka terdapat dua alternatif konsep desain dalam kenyamanan penghawaan dan pencayaan, yaitu:

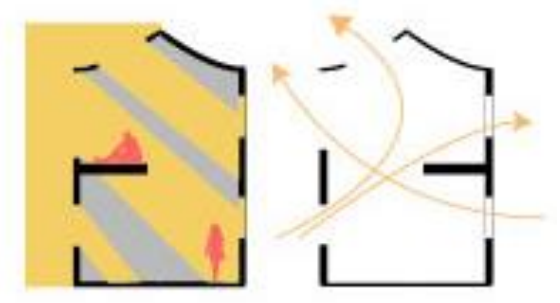

\section{Gambar 12. Konsep desain kenyamanan penghawaan dan pencahayaan dalam bangunan \\ Sumber: Hasil analisis, 2019}

Konsep desain kenyamanan penghawaan dan pencahayaan dalam bangunan memiliki void pada bagian dalam bangunan, sehingga dapat mengeluarkan hawa panas dari lantai dasar menuju lantai atas. Void juga berfungsi untuk memberikan ruang 
untuk pencahayaan yang lebih banyak di lantai dasar. Konsep desain di atas memiliki bukaan pada atap dan dinding bangunan sehingga pencahayaan dan strategi penghawaan lebih banyak. Hal tersebut bertujuan agar cahaya yang didapatkan pada ruang dalam dapat lebih banyak dan terdapat strategi penghawaan cross ventilation yang memungkinkan udara keluar lebih cepat dari sisi-sisi bangunan.

Pada perletakan ruang dalam bangunan berdasarkan solusi desain, penempatan ruang harus memperhatikan aksis bangunan. Fungsi ruang dalam dikelompokan berdasarkan modulmodul ruang dan perletakan modulmodul ruang berdasarkan hierarki ruang, yaitu public-private. Ruangan yang dekat pintu masuk adalah ruang yang lebih publik dan semakin dalam ruangannya maka semakin privat. Pembahasan akan dibagi sesuai dengan konsep desain fungsi dan bentuk bangunan yang ada pada perancangan, yaitu: hunian, rumah toko, hostel dan Museum Roemboer.

1. Pada hunian yang memiliki 2 lantai bangunan dan berbentuk $\mathrm{L}$ untuk 3 penghuni.
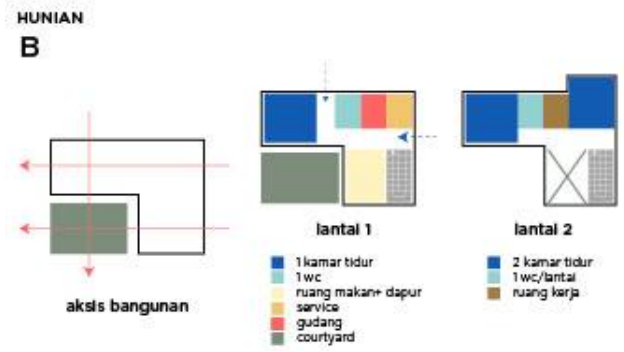

Gambar 13. Konsep desain program ruang hunian

Sumber: Hasil analisis, 2019

2. Rumah toko (restoran) memiliki 2-3 lantai bangunan dengan 3 penghuni dan memiliki alternatif bentuk linear dan persegi/ memusat.

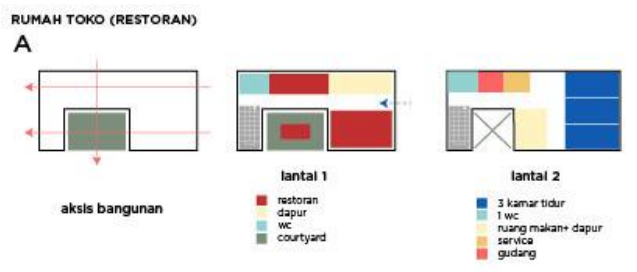

Gambar 14. Konsep desain program ruang rumah toko (restoran)

Sumber: Hasil analisis, 2019

3. Rumah toko (toko) memiliki 2-3 lantai bangunan dengan 3 penghuni dan memiliki alternatif bentuk linear dan persegi/memusat.

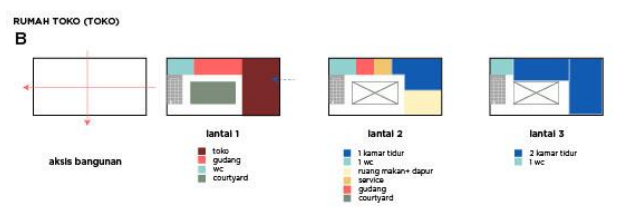

Gambar 15. Konsep desain program ruang rumah toko (toko)

Sumber: Hasil analisis, 2019

4. Hostel dan Museum Roemboer memiliki 3 lantai bangunan dan memiliki bentuk memusat serta memiliki 3 massa bangunan yang disesuaikan dengan perbandingan luas bangunan dengan luas tanah.

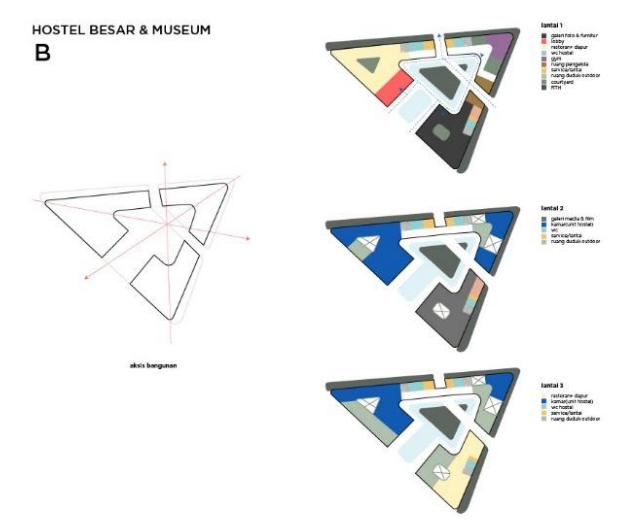

Gambar 16. Konsep desain program ruang hostel dan museum Sumber: Hasil analisis, 2019 
Konsep desain mengenai abstraksi bentuk terhadap konteks Sungai Cisadane adalah bentuk lengkung dan arc. Sehingga, penggunaan lengkung dan arc akan diterapkan pada elemen bangunan seperti pada atap dan badan bangunan. Terdapat dua alternatif konsep desain mengenai abstraksi bentuk terutama pada bagian atap bangunan yang diadaptasi dari atap renzi roof, yaitu:

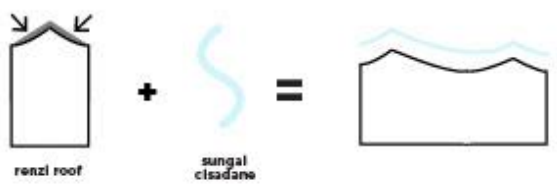

\section{Gambar 17. Konsep desain abstraksi bentuk 1}

Sumber: Hasil analisis, 2019

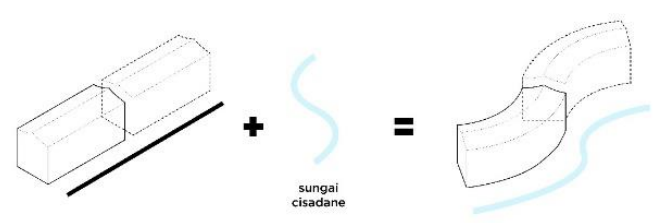

Gambar 18. Konsep desain abstraksi bentuk 2

Sumber: Hasil analisis, 2019

Kedua alternatif konsep abstraksi bentuk atap dan badan bangunan akan diterapkan dalam perancangan bangunan hunian, rumah toko, hostel dan museum. Pembahasan selanjutnya mengenai konsep desain mikro yaitu lanskap pada site.

\section{Hasil Penelitian}

Hasil Perancangan penelitian didasari oleh evaluasi konsep desain yang sudah dibahas pada subbab pembahasan sebelumnya. Berikut merupakan hasil perancangan penelitian.

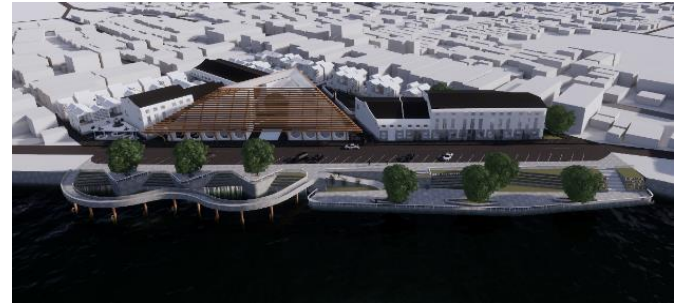

Gambar 19. Visualisasi suasana site pada mata burung 1

Sumber: Hasil analisis, 2019

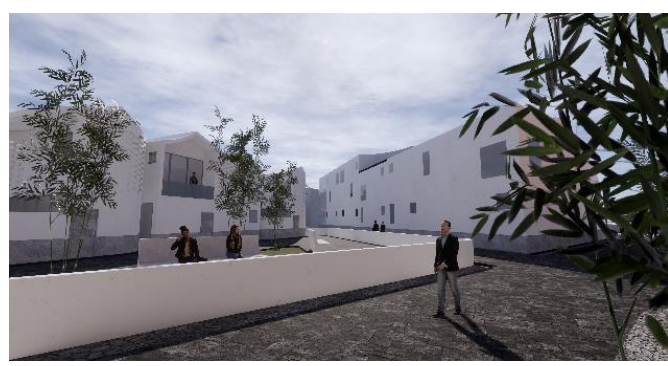

Gambar 20. Visualisasi suasana rumah 1 Sumber: Hasil analisis, 2019

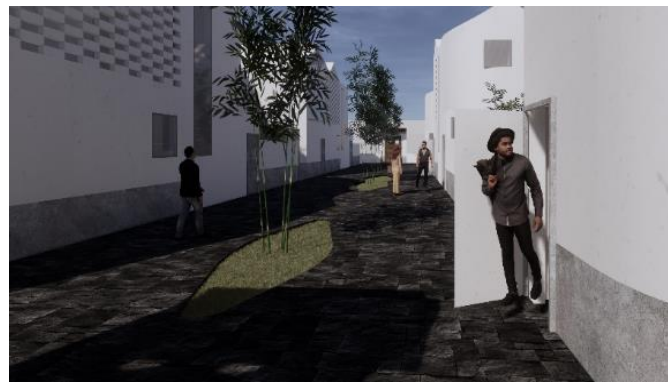

Gambar 21. Visualisasi suasana rumah 2 Sumber: Hasil analisis, 2019

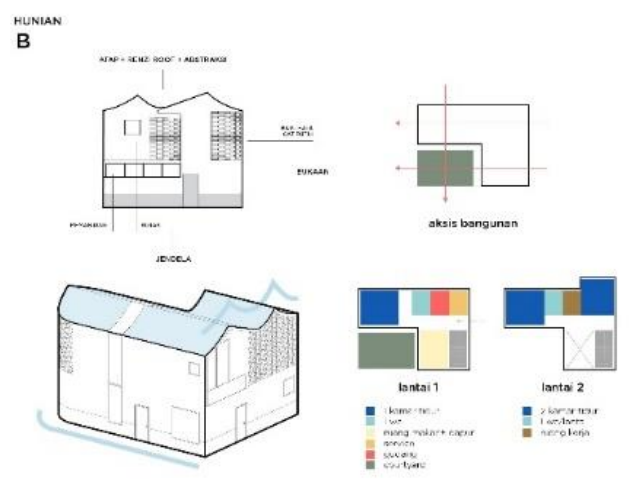

Gambar 22. Diagram perancangan hunian Sumber: Hasil analisis, 2019 

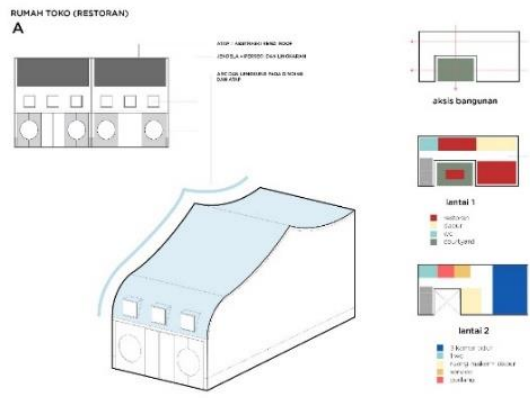

Gambar 23. Diagram perancangan ruko restoran

Sumber: Hasil analisis, 2019
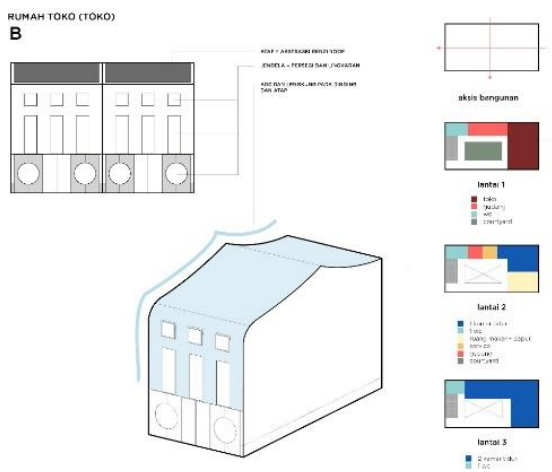

Gambar 24. Diagram perancangan ruko toko

Sumber: Hasil analisis, 2019

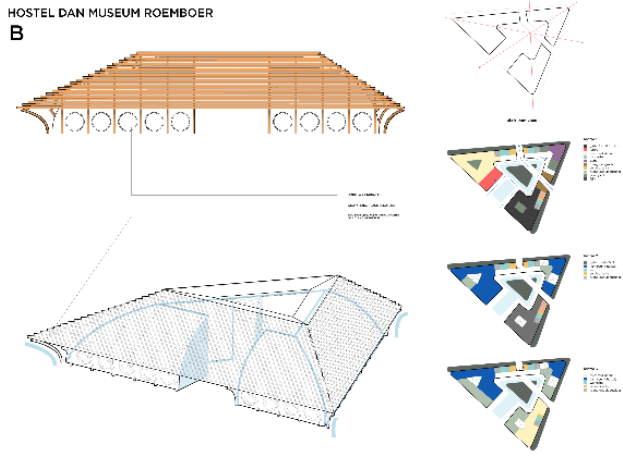

Gambar 25. Diagram perancangan hostel dan museum

Sumber: Hasil analisis, 2019

\section{Kesimpulan}

Dalam merancang suatu kawasan yang memperhatikan pengembangan fungsi hunian yang beridentitas pada area waterfront perlu diketahui fungsi apa saja yang ada pada hunian. Oleh karena itu, diperlukan beberapa kajian teori terlebih dahulu mengenai ragam fungsi hunian sebelum masuk dalam proses perancangan bangunan dan kawasan.

Pembahasan kajian teori mengenai fungsi hunian, bangunan waterfront dan kawasan yang beridentitas akan menjadi dasar bagi penulis untuk membuat kesimpulan kriteria untuk penelitian. Dalam kriteria penelitian perlu diperhatikan citra dan makna (pengalaman ruang), bangunan (kepadatan bangunan, penataan bangunan, orientasi bangunan, fasad bangunan, kenyamanan, penataan dan organisasi ruang dan abstraksi bentuk berdasarkan konteks), uses and activity (jenis fungsi, keberagaman aktivitas, aktivitas hidup dan dinamis, dan zonasi dan hubungan antar ruang), aksesibilitas dan lingkage (pengembangan akses, pola jalan dan pembagian akses), sosial budaya (fasilitas penunjang) dan letak geografis dan lanskap (kualitas lanskap, sempadan bangunan, kenyamanan dan kondisi tapak). Selain itu, terdapat studi preseden rancangan untuk penelitian sebagai contoh penerapan pengembangan fungsi hunian yang beridentitas pada area waterfront.

Setiap perancangan pada penelitian baik makro dan mikro pada kawasan akan menjadi salah satu solusi rancangan untuk mengatasi permasalahan perancangan hunian dan perelatakan fungsi ruang yang tidak tertata pada area waterfront di Pasar Lama. Perancangan kawasan dalam penelitian memperhatikan dan meningkatkan citra dari karakter kawasan dan identitas lokal setempat dengan merancang akses kawasan, 
fungsi bangunan, fasilitas penunjang, lanskap tepi air dan bangunan.

\section{Ucapan Terima Kasih}

Penelitian ini merupakan penelitian internal Tugas Akhir yang didanai oleh LPPM UPH dengan kontrak No.114/LPPM-UPH/III/2019.

\section{Daftar Pustaka}

Carmona, M., Heath, T., Oc, Taner, Tiesdell, S. (2003). Public places urban spaces: The dimensions of urban design. London: Architectural Press.

Dwitama, Daryl. (2017). Perancangan waterfront city pada kawasan Waduk Sunter Barat. Tangerang: Universitas Pelita Harapan.

Khaliesh, Hamdil. (2014). Arsitektur tradisional Tionghoa: Tinjauan terhadap identitas, karakter budaya dan eksistensinya. Jurnal Arsitektur Langkau Betang, Vol. 1, No.1, 86-99.

Ligo, Larry L. (1984). The concept of function in twentieth-century architectural criticism. New York: UMI Research Press.

Liu, Laurence G. (1989). Chinese architecture. London: Academy Edition.

Lynch, Kevin. (1960). The image of the city. London: The MIT Press. 